\title{
Episome-mediated Transfer of Drug Resistance in Enterobacteriaceae
}

\author{
X. Restriction and Modification of Phages by $\mathrm{fi}^{-} \mathrm{R}$ Factors \\ TSUTOMU WATANABE, TOSHIYA TAKANO, TOSHIHIKO ARAI, \\ HIROSHI NISHIDA, AND SACHIKO SATO \\ Department of Microbiology, Keio University School of Medicine, Tokyo, Japan
}

Received for publication 23 May 1966

\begin{abstract}
Watanabe, Tsutomu (Keio University, Tokyo, Japan), Toshiya Takano, Toshihiko ARAI, Hiroshi Nishida, AND SaCHIKo Sato. Episome-mediated transfer of drug resistance in Enterobacteriaceae. X. Restriction and modification of phages by $f i^{-}$ $\mathrm{R}$ factors. J. Bacteriol. 92:477-486. 1966.-An $f i^{-} \mathrm{R}$ factor, which restricts phages $\lambda, \mathrm{T} 1$, and $\mathrm{T} 7$ without modifying them, was found to restrict and not to modify an $\mathrm{F}^{-}$-specific phage, W-31, in Escherichia coli $\mathrm{K}-12$, but not to restrict phage P-22 in Salmonella typhimurium LT-2, whereas other $f-\mathbf{R}$ factors restricted and modified P-22 but not W-31; $f i^{+} \mathbf{R}$ factors did not restrict these phages. Transduction and lysogenization with phages $\lambda$ and P-22 were reduced by these $f i^{-} \mathrm{R}$ factors in K-12 and LT-2, respectively, and the transducing phages $\lambda$ and P-22 were modified by these $f^{-} \mathbf{R}$ factors. Spontaneous as well as ultraviolet-induced production of phage P-22 and zygotic induction of phage $\lambda$ were not significantly affected by any $\mathbf{R}$ factor. Injection of the nucleic acids of phages $T 1$ and $\lambda$ was not affected by $R$ factors, but the injected phage nucleic acids were rapidly broken down in the bacteria carrying $f^{-} \mathbf{R}$ factors. The nucleic acids of the modified phages were not broken down in these bacteria. It was assumed from these results that the mechanism of restriction of phages by $f i-\mathrm{R}$ factors is due to the breakdown of the injected phage nucleic acids by a deoxyribonuclease(s), presumably located near the cell surface in the cells carrying $f^{-} \mathrm{R}$ factors. The deoxyribonuclease(s), formed in the cells carrying the nonmodifying $f i^{-} \mathbf{R}$ factor, is considered to be different from that synthesized in the cells carrying the modifying $f_{i}-\mathbf{R}$ factors. It was further shown that the average burst sizes of the unmodified as well as modified phages are slightly reduced by the presence of the $f i^{-} \mathbf{R}$ factors.
\end{abstract}

We reported in a previous paper (31) that naturally occurring $\mathbf{R}$ factors can be classified into two types, $f^{+}$and $f^{-}$. The term $f i$ is an abbreviation for fertility inhibition, and $f^{+}$and $f^{-}$mean, respectively, the presence and absence of suppression of the function of the sex factor, F, of Escherichia coli $\mathrm{K}-12$. The function of $\mathrm{F}$ that is suppressed by the $f^{+} \mathrm{R}$ factors is possibly the formation of "F-pili" $(7,8,21,22,30)$. We found that naturally occurring $f^{+}$and $f^{-} \mathbf{R}$ factors belong to different groups in their superinfection immunity patterns, and also that some phages are restricted and modified by $f^{-} \mathbf{R}$ factors but not by $\mathrm{fi}^{+} \mathbf{R}$ factors (31). The terms "restriction" and "modification" will be used as defined by Arber (3).

The results of our studies on the restriction and modification of phages by $f^{-} \mathrm{R}$ factors, reported previously, may be summarized as follows. (i) The $f^{-} \mathbf{R}$ factors reduced the efficiency of plating (EOP) of phages $\lambda$ and T1 in $E$. coli $\mathrm{K}-12$, but $f^{+} \mathbf{R}$ factors did not have this inhibitory action. One of the $f^{-} \mathrm{R}$ factors reduced the EOP of phage T7 as well. (ii) Phages $\lambda$ and T1 underwent modifications in the hosts carrying some $f^{-} \mathbf{R}$ factors. (iii) At least two types of $f^{-} \mathbf{R}$ factors were recognized by their type of restriction and modification of these phages. (iv) Transduction of the ability to ferment galactose $\left(\mathrm{gal}^{+}\right)$with $\mathrm{Hft}$ lysates of $\lambda$ was reduced by the $f^{-} \mathbf{R}$ factors in the recipient. (v) Spontaneous production, as well as ultraviolet induction, of $\lambda$ was not affected by any $R$ factors. (vi) Adsorption of $\lambda$ and $T 1$ was not altered by the presence of any $R$ factors.

We concluded from these results that the suppression of progeny formation of these phages by 
$f^{-} \mathbf{R}$ factors is due to the inhibition of some step(s) after adsorption of the phages to the restrictive bacteria.

The above findings on the restriction and modification of phages by $f^{-} \mathbf{R}$ factors have been extended to an $\mathrm{F}^{-}$-specific phage, W-31 (32), in $E$. coli K-12 and to phage P-22 in Salmonella typhimurium LT-2. In other systems of restriction of phages, it has been shown that the phage nucleic acids undergo breakdown shortly after injection into restrictive host cells $(12,14,20,28)$. We have also studied the injection and breakdown of the phage nucleic acids in bacteria carrying $f^{-} \mathbf{R}$ factors. In parallel with our studies on the restriction and modification of phages by $f^{-} \mathbf{R}$ factors, Yoshikawa, Miyake, and Wakabayashi (33) found that the formation of $\mathrm{gal}^{+}$recombinants in the cross of a $\mathrm{gal}^{+} \lambda^{+}$Hfr strain of $E$. coli $\mathrm{K}-12$ with a $\mathrm{gal}^{-} \lambda^{-}$strain is not altered by the presence of $f^{-} \mathbf{R}$ factors in the $\mathrm{F}^{-}$recipient, and concluded that zygotic induction of phage $\lambda$ is not suppressed by the $f^{-} \mathbf{R}$ factors in the $\mathrm{F}^{-}$ recipient. We have also studied the zygotic induction of phage $\lambda$ with an $F^{-}$recipient carrying various $\mathrm{R}$ factors. These results will be reported in the present paper.

\section{Materials AND Methods}

Culture media and drugs used were those described in previous papers $(29,31)$.

Strains W3102 (gal- $\left.\lambda^{-} \mathrm{F}^{-}\right)$, CSH-2 (met $\left.\mathrm{F}^{-}\right)$, and Hfr H $3000\left(B_{1}^{-} \lambda^{+}\right)$, all of which are substrains of $E$. coli $\mathrm{K}-12$, were used. W3102 (str-r) and W3102 ( $\lambda-r$ $s t r-r$ ), streptomycin-resistant and $\lambda$ - and streptomycinresistant derivatives of $\mathrm{W} 3102$, respectively, were used as well. $S$. typhimurium LT-2 and its derivatives cysD36 (cystine-requiring) and tryD cysB-12 str-r (tryptophan- and cystine-requiring and streptomycin-resistant) were also used

Phage $\lambda$ (wild type), phage W-31 (32), and phage P-22 (wild type) were employed.

The $\mathbf{R}$ factors listed in Table 1 are the same as those described in a previous paper (31).

General phage techniques followed were those described by Adams (1), except for those which will be specified in the text.

The method for transduction of $\mathrm{gal}^{+}$with $\mathrm{Hft}$ lysates of phage $\lambda$, described in a previous paper (31), was essentially similar to the original method of Morse, Lederberg, and Lederberg (24).

The method of transduction of chromosomal genes with phage P-22 in S. typhimurium LT-2 was the same as that described by Demerec and Hartman (11).

The conditions of ultraviolet induction of phage P-22 in P-22-lysogenic $S$. typhimurium LT-2 were the same as those used in the induction of phage $\lambda$ in $E$. coli $\mathrm{K}-12$ (31).

The methods of study of lysogenization frequencies were as follows. Penassay Broth (Difco) cultures of $E$. coli W3102 and $S$. typhimurium LT-2 were infected with phages $\lambda$ and P-22, respectively, at various multi-
TABLE 1. $R$ factors employed

\begin{tabular}{|c|c|c|}
\hline $\begin{array}{l}\text { Strain no. of } \\
\text { R factor }\end{array}$ & Drug resistance markers ${ }^{a}$ & $f^{b}$ \\
\hline $\mathrm{N}-1$ & sul-r str-r tet-r & - \\
\hline N-3 & sul-r str-r tet-r & - \\
\hline R-15 & sul-r str-r & - \\
\hline 222 & sul-r str-r chl-r tet-r & + \\
\hline $\mathrm{N}-6$ & sul-r str-r tet-r & + \\
\hline N-9 & sul-r str-r tet-r & + \\
\hline
\end{tabular}

${ }^{a}$ The symbols sul-r, str-r, chl-r, and tet-r represent resistance to sulfonamide, streptomycin, chloramphenicol, and tetracycline, respectively.

${ }^{b}$ Presence $(+)$ and absence $(-)$ of suppression of the function of $\mathrm{F}$ of Escherichia coli $\mathrm{K}-12 ; f$ is the abbreviation for fertility inhibition.

plicities of infection (MOI) at $37 \mathrm{C}$. The infected cultures were aerated at $37 \mathrm{C}$ for $10 \mathrm{~min}$, diluted $1: 100$ in ice-cold Penassay Broth, and washed three times with saline in a refrigerated centrifuge to remove free phage particles. The washed, infected bacteria were diluted with saline and plated on nutrient agar for colony isolation. After overnight incubation of the inoculated plates, the developed colonies were replicaplated onto soft nutrient agar layers seeded with indicators of the phages on the top of ordinary nutrient agar. After the replica plates were incubated overnight at $37 \mathrm{C}$, colonies with surrounding lytic zones were regarded as lysogenic and the others as nonlysogenic.

The method of study of zygotic induction of phage $\lambda$ was the same as that described by Jacob and Wollman (16-18). The only difference was that we employed W3102 ( $\lambda-r$ str- $r$ ) carrying various $\mathrm{R}$ factors as recipients in the crosses with $\mathrm{Hfr} H 3000\left(\lambda^{+}\right)$.

The method of study of injection of phage nucleic acids was as follows. $\mathrm{P}^{32}$-labeled phages were prepared mainly by the procedure of Hershey and Chase (15). W3102 was grown with aeration in radioactive $\mathrm{H}$ medium (containing $P^{32}$ at a specific activity of $15 \mathrm{mc} / \mathrm{mg}$ of $P$ ) and infected with phage T1 at a MOI of 0.01 . For preparing radioactive phage $\lambda, \mathrm{CSH}-2$ was grown in a similar radioactive $\mathrm{H}$ medium and irradiated with ultraviolet light for phage induction. After almost complete clearing of the cultures, the lysates were centrifuged at $8,000 \mathrm{rev} / \mathrm{min}$ for $30 \mathrm{~min}$. Pancreatic deoxyribonuclease (Sigma Chemical Co., St. Louis, Mo.) and pancreatic ribonuclease (Sigma) were added to the supernatant fractions (10 and $25 \mu \mathrm{g} / \mathrm{ml}$, respectively); the preparations were incubated at $37 \mathrm{C}$ for $90 \mathrm{~min}$, for digestion of the free nucleic acids, and were then centrifuged at $30,000 \mathrm{rev} / \mathrm{min}$ for $60 \mathrm{~min}$. The sediment was suspended in tris(hydroxymethyl)aminomethane (Tris)-magnesium buffer $(p H$ 7.5) containing $10 \mathrm{~mm}$ Tris- $\mathrm{HCl}$ and $\mathrm{MgCl}_{2}$. (The volume of buffer used for suspension was $5 \%$ of the volume of the original lysates.) $\mathbf{P}^{32}$-labeled phages in these suspensions were purified by sucrose density gradient centrifugation (5 to $20 \%$ sucrose in Tris-magnesium buffer) at $17,500 \mathrm{rev} / \mathrm{min}$ for $60 \mathrm{~min}(9,25)$. Injection of phage nucleic acids was studied by the procedure of 
Watanabe and Okada (32), a minor modification of the original method of Hershey and Chase (15).

The method used to study the breakdown of the injected phage nucleic acids was similar to that of Dussoix and Arber (12). Bacteria were grown in Lennox broth at $37 \mathrm{C}$ with aeration, and the exponentially growing cells were centrifuged and resuspended in fresh Lennox broth to about $10^{\circ}$ cells per milliliter. To $4.9 \mathrm{ml}$ of this bacterial suspension was added $0.1 \mathrm{ml}$ of the radioactive phage suspension with a titer of $10^{9}$ plaque-forming units $/ \mathrm{ml}$. The phage-infected bacteria were aerated at $37 \mathrm{C}$, and $0.7-\mathrm{ml}$ samples were taken periodically and added to equal volumes of $5 \%$ cold trichloroacetic acid. These samples were kept in an ice bath for $30 \mathrm{~min}$, and were then centrifuged in the cold at $2,500 \mathrm{rev} / \mathrm{min}$ for $20 \mathrm{~min}$. The radioactivity of heat-dried samples of the supernatant fluids was determined. The sediments were dissolved in $2 \mathrm{~N}$ $\mathrm{NH}_{4} \mathrm{OH}$, heat-dried, and tested for radioactivity. In parallel with these determinations, the samples taken at $3 \mathrm{~min}$ after infection were centrifuged at $8,000 \mathrm{rev} /$ min, and the radioactivity of the supernatant fluids was determined.

\section{RESULTS}

Phage W-31, which was grown on W3102 ( $\left.\mathbf{R}^{-}\right)$, was plated on W3102 strains with and without $R$ factors. The EOP and plaque size of W-31 were slightly reduced only on W3102 (N-1); if we take the titer of the phage on W3102 $\left(R^{-}\right)$as 1 , the EOP of this phage on W3102 (N-1) was about $5 \times 10^{-1}$. Modification of this phage did not occur upon its growth on W3102 (N-1).

The frequency of lysogenization with phage $\lambda$ was strongly reduced by the presence of $f^{-} \mathbf{R}$ factors in W3102 (Table 2). Surviving bacteria were about equal in number in all of the phageinfected W3102 strains with and without $R$ factors.

Lft lysates of phage $\lambda$, obtained by ultraviolet irradiation of $\mathrm{CSH}-2$, were used for transducing $\mathrm{gal}^{+}$into W3102 strains with and without R factors. The $\mathrm{gal}^{+} \mathbf{L f t}$ transductants obtained were further ultraviolet-irradiated, and the $\mathrm{Hft}$ lysates obtained were used for the transduction of $\mathrm{gal}^{+}$ into W3102 strains with and without $R$ factors. Phage $\lambda \mathrm{dg}$, like normal $\lambda$, was restricted by $f^{-} \mathbf{R}$ factors; $\lambda$ dg was also modified in N-3 and R-15 by both of these $f^{-} \mathrm{R}$ factors, whereas it was not modified in N-1 (Table 3). Restriction and modification of $\lambda \mathrm{dg}$ was previously reported to occur in P1-lysogenic bacteria (2). It may be worthwhile to point out that the suppression of $\mathrm{gal}^{+}$transduction by $f^{-} \mathbf{R}$ factors was not as severe as the reduction of EOP of normal $\lambda$ (31).

Mating mixtures of $\mathrm{Hfr} \mathrm{H} 3000\left(\lambda^{+}\right)$and W3102 $(\lambda-r$ str-r) with and without $\mathbf{R}$ factors were interrupted at $60 \mathrm{~min}$ by blending, diluted in saline, and then plated in soft nutrient agar containing $1,000 \mu \mathrm{g} / \mathrm{ml}$ of streptomycin with W3102 (str-r) as an indicator of phage $\lambda$. It was found that zygotic induction of phage $\lambda$ is not significantly suppressed by any $R$ factors in the $\mathrm{F}^{-}$recipient.

Titration of phage P-22 propagated on LT-2 $\left(\mathrm{R}^{-}\right)$was carried out with LT-2 strains with and without $\mathbf{R}$ factors as indicators. It was found that the EOP of P-22 was reduced by $f^{-}$R factors N-3 and $\mathrm{R}-15$, but not by $f^{-} \mathrm{R}$ factor $\mathrm{N}-1$ or by $f^{+} \mathrm{R}$ factor 222 (Table 4). Plaques of P-22 on the

TABLE 2. Frequencies of lysogenization with phage $\lambda$ of Escherichia coli W3102a strains carrying various $R$ factors

\begin{tabular}{l|c|c}
\hline \multirow{2}{*}{ Strain } & \multicolumn{2}{|c}{ Frequency of lysogenized colonies ${ }^{b}$} \\
\cline { 2 - 3 } & $\begin{array}{c}\text { No. of lysogenized } \\
\text { colonies/no. studied }\end{array}$ & Per cent \\
\hline W3102 (R-) & $20 / 127$ & 15.7 \\
W3120 (N-1) & $8 / 298$ & 2.7 \\
W3102 (N-3) & $1 / 328$ & 0.3 \\
W3102 (R-15) & $17 / 450$ & 3.8 \\
W3102 (222) & $28 / 127$ & 22.0 \\
\hline
\end{tabular}

${ }^{a} \mathrm{~W} 3102$ is a $\mathrm{gal}^{-} \lambda^{-} \mathrm{F}^{-}$mutant of $E$. coli $\mathrm{K}-12$.

${ }^{b}$ Each bacterial culture was infected with phage $\lambda$ in Penassay Broth at a multiplicity of infection of 10. The infected culture was washed thoroughly and plated on nutrient agar for colony isolation. The resultant colonies were replica-plated onto soft nutrient agar seeded with W3102 $\left(\mathbf{R}^{-}\right)$on top of ordinary nutrient agar.

TABLE 3. Host-induced modification of phage $\lambda d g$ on Escherichia coli W3102a strains carrying various $R$ factors

\begin{tabular}{|c|c|c|c|c|}
\hline \multirow{2}{*}{ Hft lysate of $\lambda$ prepared on } & \multicolumn{4}{|c|}{ Frequency of transduction of ability to ferment galactose in recipient } \\
\hline & W3102 $\left(\mathbf{R}^{-}\right)$ & W3102 (N-1) & W3102 (N-3) & W3102 $(R-15)$ \\
\hline $\begin{array}{ll}\text { W3102 } & \left(\mathrm{R}^{-}\right) \\
\text {W3102 } & (\mathrm{N}-1) \\
\text { W3102 } & (\mathrm{N}-3) \\
\text { W3102 } & \text { (R-15) }\end{array}$ & $\begin{array}{l}2.3 \times 10^{-3} \\
3.1 \times 10^{-3} \\
2.0 \times 10^{-3} \\
2.7 \times 10^{-3}\end{array}$ & $\begin{array}{l}3.1 \times 10^{-4} \\
1.0 \times 10^{-5} \\
2.0 \times 10^{-5} \\
1.4 \times 10^{-4}\end{array}$ & $\begin{array}{l}3.4 \times 10^{-4} \\
4.3 \times 10^{-5} \\
1.5 \times 10^{-3} \\
6.7 \times 10^{-3}\end{array}$ & $\begin{array}{l}1.0 \times 10^{-5} \\
5.0 \times 10^{-5} \\
2.6 \times 10^{-3} \\
1.8 \times 10^{-3}\end{array}$ \\
\hline
\end{tabular}

a W3102 is a $\mathrm{gal}^{-} \lambda^{-} \mathrm{F}^{-}$mutant of $E$. coli $\mathrm{K}-12$. 
indicator strains carrying $\mathrm{N}-3$ and $\mathrm{R}-15$ were similar in shape but slightly smaller than those on the other indicator strains. P-22 was also modified by N-3 and R-15 (Table 4).

Phage P-22 grown on LT-2 (wild type) was used for transducing prototrophy into auxotrophic mutant strains of LT-2 with and without $R$ factors. The frequencies of transductants were reduced by the presence of $\mathrm{N}-3$ in the recipients (Table 5). R-15 gave comparable results, but no other R factor was inhibitory. Only complete transductants, and no abortive transductants (26), were counted in this experiment, because the frequencies of the latter were not reproducible. It may be worthwhile to emphasize that the reduction of transduction frequencies by N-3 and R-15 was less severe than the reduction of EOP by these $\mathbf{R}$ factors (Tables 4 and 5). When phage P-22, propagated on wild-type LT-2 carrying $\mathrm{N}-3$, was used for transducing prototrophy into auxotrophic mutants of LT-2 carrying N-3, it was shown that transducing phage P-22 was also modified by $\mathrm{N}-3$ (Table 5). Comparable results were again obtained with $\mathrm{R}-15$.

The frequencies of lysogenization with phage P-22 were also markedly reduced by the presence of N-3 and R-15 in LT-2 (Table 6). The number of surviving bacteria were about equal in all of the phage-infected LT-2 strains with and without $R$ factors.

The effect of various $\mathrm{R}$ factors on the adsorption of phage P-22 was studied. LT-2 strains with and without $\mathrm{R}$ factors were grown in Penassay Broth at $37 \mathrm{C}$ with aeration to about $5 \times 10^{8}$ cells per milliliter; $9 \mathrm{ml}$ of each culture was mixed with $1 \mathrm{ml}$ of phage P-22 grown on LT-2 ( $\left.\mathbf{R}^{-}\right)$, $5 \times 10^{7}$ per milliliter, and aerated at $37 \mathrm{C}$. Samples $(0.1 \mathrm{ml})$ were taken at various times, diluted with ice-cold Penassay Broth $(1: 100)$, and then centrifuged at $5,000 \mathrm{rev} / \mathrm{min}$ for $5 \mathrm{~min}$ in the cold. The supernatant fluids were treated with chloroform and assayed for free phage. There was no significant difference in the adsorption rates of P-22 to LT-2, with or without R factors.

Phage P-22 of lysogenic LT-2 strains with and without $\mathbf{R}$ factors was induced with ultraviolet light, and dose-response curves were obtained. No significant difference could be found in ultraviolet inducibility of phage P-22 in these strains. Spontaneous liberation of phage P-22 was also unaffected by any $\mathbf{R}$ factors.

Furthermore, no significant difference was found in the extent of injection of the nucleic acid of $\mathrm{P}^{32}$-labeled phage $\mathrm{T} 1$ into W3102 strains with and without $\mathrm{R}$ factors (Table 7). Essentially

TABLE 4. Efficiencies of plating of phage P-22 on Salmonella typhimurium LT-2 strains carrying various $R$ factors

\begin{tabular}{|c|c|c|c|c|c|}
\hline \multirow{2}{*}{ P-22 groVn on } & \multicolumn{5}{|c|}{ Efficiency of plating on } \\
\hline & $\mathrm{LT}-2\left(\mathrm{R}^{-}\right)$ & LT-2 (N-1) & LT-2 (N-3) & LT-2 (R-15) & LT-2 (222) \\
\hline LT-2 ( $\left.\mathbf{R}^{-}\right)$ & 1 & $9.5 \times 10^{-1}$ & $4.8 \times 10^{-4}$ & $2.7 \times 10^{-4}$ & $7.2 \times 10^{-1}$ \\
\hline $\mathbf{L T}-2(\mathrm{~N}-3)$ & 1 & $8.0 \times 10^{-1}$ & 1.2 & 1.1 & $8.0 \times 10^{-1}$ \\
\hline LT-2 (R-15) & 1 & $7.3 \times 10^{-1}$ & $9.0 \times 10^{-1}$ & 1.0 & 1.0 \\
\hline
\end{tabular}

TABLE 5. Frequencies of transduction with phage P-22 of prototrophy into auxotrophic mutants of Salmonella typhimurium LT-2 strains carrying carious $R$ factors

\begin{tabular}{|c|c|c|c|}
\hline $\mathrm{P}-22$ grown on & Recipient $^{a}$ & Selected marker ${ }^{b}$ & $\begin{array}{l}\text { Frequency of transductants } \\
\text { (per plaque-forming unit) }\end{array}$ \\
\hline $\mathbf{L T}-\mathbf{2}\left(\mathbf{R}^{-}\right)$ & cys D-36 & $c y s^{+}$ & $6.5 \times 10^{-6}$ \\
\hline $\mathbf{L T}-2\left(\mathbf{R}^{-}\right)$ & $\operatorname{cys} D-36(\mathrm{~N}-3)$ & cys $s^{+}$ & $6.7 \times 10^{-7}$ \\
\hline LT-2 (N-3) & cys $D-36$ & $c y s^{+}$ & $1.1 \times 10^{-5}$ \\
\hline $\mathrm{LT}-2(\mathrm{~N}-3)$ & $\operatorname{cys} D-36(\mathrm{~N}-3)$ & cys $s^{+}$ & $1.3 \times 10^{-5}$ \\
\hline $\mathrm{LT}-2\left(\mathbf{R}^{-}\right)$ & $\operatorname{try} D$ cys $B-12$ str-r & $\operatorname{try} y^{+}$ & $1.7 \times 10^{-5}$ \\
\hline $\mathbf{L T}-2\left(\mathbf{R}^{-}\right)$ & $\operatorname{try} D$ cys $B-12$ str-r $(\mathrm{N}-3)$ & $t r y^{+}$ & $3.2 \times 10^{-6}$ \\
\hline LT-2 (N-3) & $\operatorname{try} D$ cys $B-12$ str-r & $\operatorname{try} y^{+}$ & $3.5 \times 10^{-5}$ \\
\hline LT-2 (N-3) & $\operatorname{try} D$ cys $B-12$ str-r (N-3) & $\operatorname{try} y^{+}$ & $3.3 \times 10^{-5}$ \\
\hline
\end{tabular}

${ }^{a}$ Recipient strains cys D-36 and tryD cysB-12 str-r are both substrains of $S$. typhimurium LT-2; cys D-36 requires cystine, and $\operatorname{try} D$ cys $B-12$ str-r requires tryptophan and cystine and is resistant to streptomycin.

${ }^{b}$ The symbols $\mathrm{cys}^{+}$and $t r y^{+}$represent nonrequirement of cystine and tryptophan, respectively. 
similar results were obtained with $\mathrm{P}^{32}$-labeled phage $\lambda$.

The fate of the injected phage nucleic acids was then studied. Figure 1A shows the kinetics of liberation of cold trichloroacetic acid-soluble $\mathrm{P}^{32}$ fraction after infection with $P^{32}$-labeled phage $T 1$ of W3102 strains with and without $R$ factors. The nucleic acid of phage T1 grown on W3102 $\left(R^{-}\right)$ was rapidly broken down in the host bacteria carrying $f^{-} \mathbf{R}$ factors; more than $40 \%$ of the adsorbed phage nucleic acid was broken down within $10 \mathrm{~min}$. In contrast, the nucleic acid of the phage was broken down less than $10 \%$ in W3102 $\left(\mathrm{R}^{-}\right)$and W3102 (222). The nucleic acid of phage T1 grown on W3102 (N-3) and modified to both $\mathrm{N}-3$ and R-15 was not broken down by more than $10 \%$ in W3102 ( $\left.\mathrm{R}^{-}\right)$, W3102 (N-3), and W3102 (R-15) but was broken down by about $40 \%$ in W3102 (N-1) as seen in (Fig. 1B). Comparable results were obtained with phage $\lambda$.

It was reported previously (31) that phage $\lambda$ does not form visible plaques on $\mathrm{W} 3102(\mathrm{~N}-1)$ and that the plaques of phage $\mathrm{T} 1$ on this indicator

TABLE 6. Frequencies of lysogenization with phage $P$-22 of Salmonella typhimurium LT-2 strains carrying various $R$ factors

\begin{tabular}{c|c|c}
\hline \multirow{2}{*}{ Strain } & \multicolumn{2}{|c}{ Frequency of lysogenized colonies ${ }^{a}$} \\
\cline { 2 - 3 } & $\begin{array}{c}\text { No. of lysogenized } \\
\text { colonies/no. studied }\end{array}$ & Per cent \\
\hline LT-2 ( $\left.\mathbf{R}^{-}\right)$ & $534 / 1,088$ & 49.1 \\
LT-2 (N-1) & $153 / 193$ & 79.3 \\
LT-2 (N-3) & $1 / 1,796$ & 0.06 \\
LT-2 (R-15) & $0 / 1,076$ & $<0.09$ \\
LT-2 (222) & $138 / 175$ & 78.9 \\
\hline
\end{tabular}

${ }^{a}$ Each bacterial culture was infected with phage P-22 in Penassay Broth at a multiplicity of infection of 1. The infected culture was washed thoroughly and plated on nutrient agar for colony isolation. The resultant colonies were replicaplated onto a soft nutrient agar layer seeded with LT-2 ( $\left.\mathbf{R}^{-}\right)$on the top of ordinary nutrient agar. strain are much smaller than those on W3102 strains without $\mathbf{R}$ factors, with $f^{+} \mathbf{R}$ factors, and with $f^{-} \mathbf{R}$ factors $\mathrm{N}-3$ and $\mathrm{R}-15$. No difference was found in the morphology of plaques of phages $\lambda$ and T1 on W3102 strains without R factors, with $f^{+} \mathbf{R}$ factors, and with $f^{-} \mathbf{R}$ factors $\mathbf{N}-3$ and R-15. However, when the size of the plaques of phages $T 1$ and $\lambda$ was carefully re-examined in recent experiments, it was noted that the plaques of these phages on W3102 (N-3) and W3102 (R-15) were slightly but definitely smaller than those on W3102 strains without $R$ factors and with $f^{+} \mathbf{R}$ factors. Identical results were obtained also with phages $\lambda$ and T1 modified to $\mathrm{N}-3$ and $\mathrm{R}-15$. These results suggested to us the possibility that the formation of progeny of these phages may be suppressed by the presence of these $f^{-} \mathbf{R}$ factors. Accordingly, the following experiments were undertaken with phage $\mathrm{T} 1$.

Since it was not possible to prepare a high-titer anti-T1 serum, as pointed out by Adams (1), we attempted in one-step growth experiments with $\mathrm{T} 1$ to remove free phage by washing with repeated centrifugation and resuspension. Penassay Broth cultures of W3102 strains with and without R factors were treated with $0.002 \mathrm{M} \mathrm{KCN}$ and then infected with phage T1 at a MOI of 0.1. In other experiments, the bacteria grown in Penassay Broth were washed and resuspended in $\mathrm{T} 2$ buffer (15), starved by aeration at $37 \mathrm{C}$ for $30 \mathrm{~min}$, and then infected wiih phage $\mathrm{T} 1$ at a similar MOI. The cultures infected under these conditions were washed four times with $\mathrm{T} 2$ buffer by repeated centrifugation and resuspension in the cold. The washed, infected bacteria were resuspended in cold Penassay Broth and then diluted in the same broth kept at $37 \mathrm{C}$ to cell concentrations of $10^{4}$ to $10^{5}$ per milliliter. They were then aerated at $37 \mathrm{C}$, and $0.1-\mathrm{ml}$ samples were periodically taken for determination of the infective centers. The results of such one-step growth experiments with phage $T 1$ propagated on $\mathrm{W} 3102\left(\mathrm{R}^{-}\right)$are shown in Fig. 2A. The counts of bacterial infective centers of $\mathrm{W} 3102$, with and without $R$ factors,

TABEL 7. Injection of nucleic acid of $P^{32}$-labeled phage T1 into Escherichia coli W3102 strains carrying various $R$ factors

\begin{tabular}{|c|c|c|c|c|}
\hline \multirow{2}{*}{ Strain } & \multirow{2}{*}{$\mathbf{P}^{32}$ adsorbed to bacteria ${ }^{a}$} & \multicolumn{2}{|c|}{$\mathrm{P}^{32}$ after blending ${ }^{a}$ in } & \multirow{2}{*}{$\begin{array}{c}P^{32} \text { in sediment after } \\
\text { blending }\end{array}$} \\
\hline & & Supernatant fluid & Sediment & \\
\hline $\begin{array}{ll}\text { W31-2 } & \left(\mathbf{R}^{-}\right) \\
\text {W3102 } & (\mathrm{N}-1) \\
\text { W3102 } & (\mathrm{N}-3) \\
\text { W3102 } & (222)\end{array}$ & $\begin{array}{l}2.59 \times 10^{4} \\
1.96 \times 10^{4} \\
7.99 \times 10^{3} \\
8.64 \times 10^{3}\end{array}$ & $\begin{array}{l}8.53 \times 10^{3} \\
6.83 \times 10^{3} \\
3.70 \times 10^{3} \\
3.66 \times 10^{3}\end{array}$ & $\begin{array}{l}1.39 \times 10^{4} \\
9.27 \times 10^{3} \\
3.34 \times 10^{3} \\
3.54 \times 10^{3}\end{array}$ & $\begin{array}{c}\% \\
62.1 \\
57.5 \\
47.5 \\
49.2\end{array}$ \\
\hline
\end{tabular}

$a$ Values (counts per minute) obtained from 1-ml samples after heat-drying. 

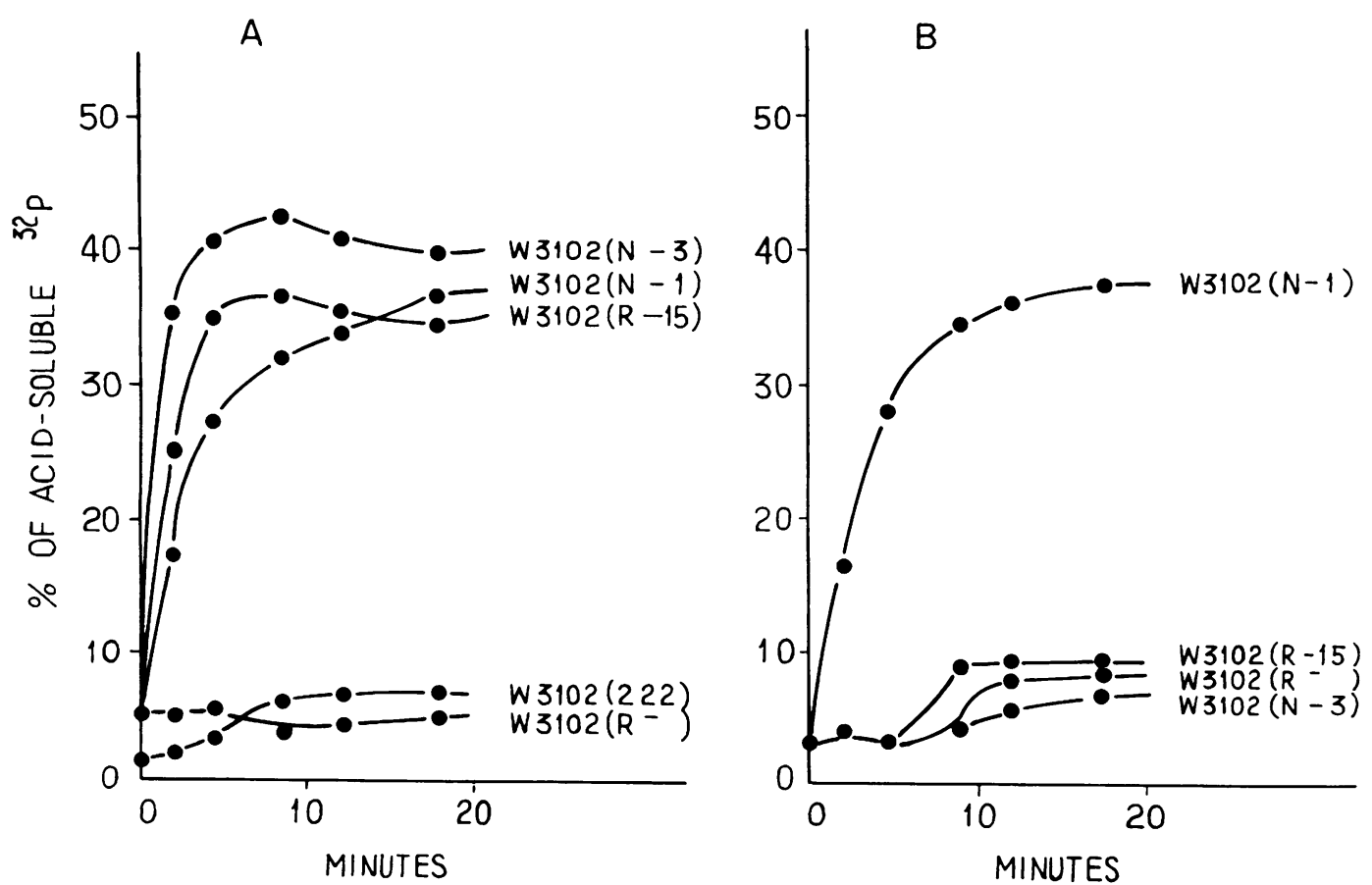

FIG. 1. Breakdown of nucleic acid of $P^{32}$-labeled $T 1$ in Escherichia coli W3102 strains carrying various $R$ factors. $(A)$ Kinetics of formation of cold trichloroacetic acid-soluble $P^{32}$ fraction in the infection, with $P^{32}$-labeled $T 1$ grown on W3102 $\left(R^{-}\right)$, of W3102 strains with and without $R$ factors. (B) Similar kinetics in the infection, with $P^{32}$-labeled T1 grown on W3102 (N-3), of W3102 strains with and without R factors.

before the liberation of progeny phage were in parallel with the EOP of the phage on these indicator strains. In addition, the latent period of T1 was not detectably altered by the presence of any $\mathbf{R}$ factors in the host bacteria. The average burst size of the phage, however, seemed to be slightly reduced in the hosts with $f^{-} \mathrm{R}$ factors, especially with $\mathrm{N}-3$ and $\mathrm{R}-15$. The reduction in burst size in these strains was more marked when the host bacteria were starved before infection. One-step growth curves of $\mathrm{T} 1$ were similar when the phage grown on $\mathrm{W} 3102(\mathrm{~N}-3)$ and modified to N-3 and R-15 was used (Fig. 2B).

Single-burst experiments with phage $\mathrm{T} 1$ were then carried out in the hosts carrying various $\mathbf{R}$ factors. W3102 strains with and without $R$ factors, grown at $37 \mathrm{C}$ with aeration in Penassay Broth, were treated with $0.002 \mathrm{M} \mathrm{KCN}$ or starved by the procedures described above for one-step growth experiments. They were infected with phage T1 at a MOI of 0.1 , and the infected bacteria were thoroughly washed with T2 buffer. They were then diluted with Penassay Broth so that $1 \mathrm{ml}$ contained about 0.5 cell with a potentiality of liberating progeny phage. These bacterial suspensions were distributed into a series of small test tubes,
$1 \mathrm{ml}$ in each, and incubated at $37 \mathrm{C}$ for $40 \mathrm{~min}$. The contents of each tube were plated in $3 \mathrm{ml}$ of soft nutrient agar with indicator strain W3102 for determining the free phage. The average burst sizes of $\mathrm{T} 1$ in single-burst experiments are shown in Table 8. It can be seen that the burst size of this phage was reduced by the presence of $f^{-} \mathbf{R}$ factors, especially $\mathrm{N}-3$. This tendency was more marked when the starved bacteria were infected as in one-step growth experiments. Comparable data were obtained also with phage $\mathrm{T} 1$ modified by $\mathrm{N}-3$. Furthermore, it was shown that $\mathrm{T} 1$ was fully modified to N-3 by growing on W3102 (N-3) for a single cycle, as determined by plating the divided portions of the single-burst samples on both W3102 ( $\left.\mathbf{R}^{-}\right)$and W3102 (N-3). Conversely, when the single-burst samples from W3102 $\left(\mathbf{R}^{-}\right)$ infected with $\mathrm{T} 1$, which had been modified by $\mathrm{N}-3$, were plated on W3102 ( $\mathrm{R}^{-}$) and W3102 (N-3), it was found that the modification of T1 was completely lost during a single growth cycle on the $\mathrm{R}^{-}$strain. These results clearly demonstrate, on the single infected-cell level, that the observed phenomena are really host-controlled modifications of the phage. 


\section{Discussion}

The results indicate that the formation of plaques by phage W-31 on E. coli $\mathrm{K}-12$ and by phage P-22 on $S$. typhimurium LT-2 are reduced
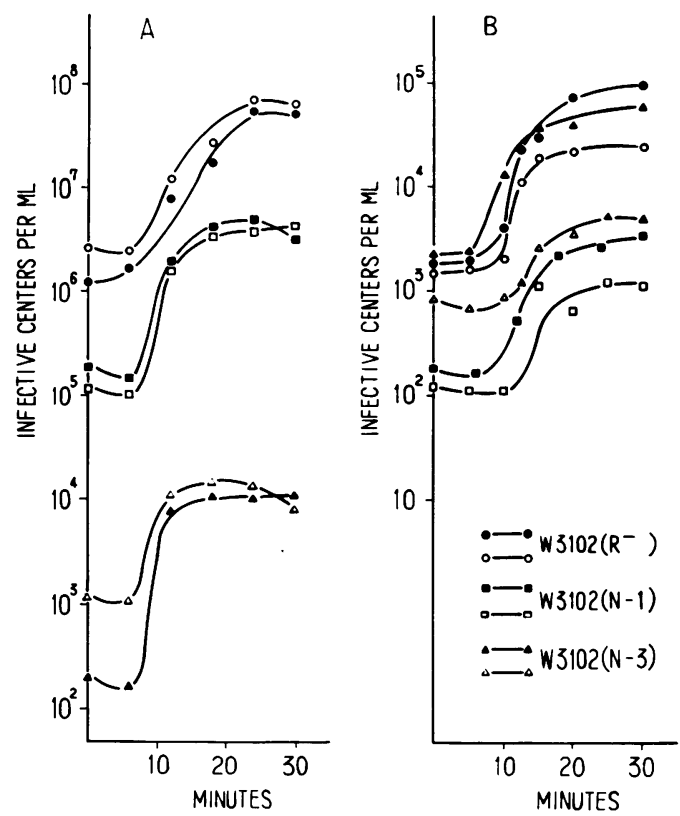

Fig. 2. One-step growth curves of phage $T 1$ in Escherichia coli W3102 (gal $\left.\lambda^{-} \boldsymbol{F}^{-}\right)$strains carrying various $R$ factors. $(A)$ One-step growth curves of $T 1$, previously grown on W3102 $\left(R^{-}\right) .(B)$ One-step growth curves of T1, previously grown on W3102 (N-3). The curves with solid symbols represent bacteria infected with T1 after treatment with $0.002 \mathrm{M} \mathrm{KCN}$ in Penassay Broth. The curves with open symbols represent bacteria infected with T1 after starvation in T2 buffer (15) for 30 min at $37 C$. by some $f^{-} \mathbf{R}$ factors but not by $f^{+} \mathbf{R}$ factors. Phage P-22 was also modified by the restricting $f^{-} \mathrm{R}$ factors. The patterns of restriction and modification of these phages by $R$ factors, reported here and in a previous paper (31), may be summarized as in Table 9. Not only was the formation of plaques of these phages suppressed by the $f^{-} \mathbf{R}$ factors, but also the frequencies of lysogenization of K-12 with phage $\lambda$ and of LT-2 with phage $\mathbf{P}-22$ were reduced by the $f^{-} \mathbf{R}$ factors. Furthermore, the frequencies of $\mathrm{gal}^{+}$transduction with $\lambda \mathrm{dg}$ into a $\mathrm{gal}^{-}$mutant of $\mathrm{K}-12$ and of transduction with P-22 of prototrophy into auxotrophic mutants of LT-2 were reduced by the $f^{-}$ $\mathrm{R}$ factors in the recipients. It was also shown that

TABLE 8. Average burst sizes (1) of phage T1 in Escherichia coli W3102 ${ }^{a}$ carrying various $R$ factors studied by single-burst experiments

\begin{tabular}{|c|c|c|c|c|}
\hline \multirow{2}{*}{ Phage T1 grown on } & \multirow{2}{*}{$\begin{array}{c}\text { Condition of host } \\
\text { bacteria at the } \\
\text { time of phage } \\
\text { infection }\end{array}$} & \multicolumn{3}{|c|}{ Average burst size on } \\
\hline & & $\begin{array}{l}\text { W3102 } \\
\left(\mathrm{R}^{-}\right)\end{array}$ & $\begin{array}{l}\text { W3102 } \\
(\mathrm{N}-1)\end{array}$ & $\begin{array}{l}\text { W3102 } \\
(\mathrm{N}-3)\end{array}$ \\
\hline \multirow[t]{2}{*}{ W3102 ( $\left.\mathbf{R}^{-}\right)$} & Treated with & 39.3 & 27.1 & 24.0 \\
\hline & Starved $c$ & 31.3 & 31.8 & 8.1 \\
\hline \multirow[t]{2}{*}{ W3102 (N-3) } & $\begin{array}{l}\text { Treated with } \\
\text { KCN }\end{array}$ & 28.8 & 23.3 & 15.6 \\
\hline & Starved & 28.3 & 21.4 & 9.0 \\
\hline
\end{tabular}

${ }^{a} \mathrm{~W} 3102$ is a $\mathrm{gat}^{-} \lambda^{-} \mathrm{F}^{-}$mutant of $E$. coli $\mathrm{K}-12$

${ }^{b}$ Bacteria in Penassay Broth were treated with $0.002 \mathrm{M} \mathrm{KCN}$, and infected with $\mathrm{T} 1$ at a multiplicity of infection of 0.1 . The infected bacteria were washed in the cold and resuspended in fresh Penassay Broth.

c Bacteria were starved by aerating the $\mathrm{T} 2$ buffer suspension at $37 \mathrm{C}$ for $30 \mathrm{~min}$.

TABLE 9. Summary of restrictions and modifications of phages by $R$ factors

\begin{tabular}{|c|c|c|c|c|c|c|c|}
\hline \multirow{2}{*}{$\begin{array}{l}\text { Strain no. of } R \\
\text { factor }\end{array}$} & \multirow{2}{*}{$f^{a}$} & \multirow{2}{*}{ Response of phage } & \multicolumn{5}{|c|}{ Phage } \\
\hline & & & $\lambda$ & T1 & T7 & W-31 & P-22 \\
\hline $\mathrm{N}-1 \ldots \ldots$ & - & $\begin{array}{l}\text { Restriction } \\
\text { Modification }\end{array}$ & \pm & \pm & \pm & $\begin{array}{l}+ \\
-\end{array}$ & $\begin{array}{l}- \\
-\end{array}$ \\
\hline $\mathrm{N}-3$. & - & $\begin{array}{l}\text { Restriction } \\
\text { Modification }^{b}\end{array}$ & $\begin{array}{l}+ \\
+\end{array}$ & $\begin{array}{l}+ \\
+\end{array}$ & - & - & $\begin{array}{l}+ \\
+\end{array}$ \\
\hline R-15. . & - & $\begin{array}{l}\text { Restriction } \\
\text { Modification }^{b}\end{array}$ & $\begin{array}{l}+ \\
+\end{array}$ & $\begin{array}{l}+ \\
+\end{array}$ & - & - & $\begin{array}{l}+ \\
+\end{array}$ \\
\hline $222, \mathrm{~N}-6, \mathrm{~N}-9$. & + & $\begin{array}{l}\text { Restriction } \\
\text { Modification }\end{array}$ & $\begin{array}{l}- \\
-\end{array}$ & $\overline{-}$ & - & - & $\overline{-}$ \\
\hline
\end{tabular}

a Presence (+) and absence (-) of suppression of the function of $\mathrm{F}$ of Escherichia coli $\mathrm{K}-12 ; f i$ is the abbreviation for fertility inhibition.

${ }^{b}$ Modification of phages by N-3 and R-15 occur simultaneously to both of these $\mathrm{R}$ factors. 
the transducing phage $\lambda \mathrm{dg}$ and the transducing phage P-22 of prototrophy are modified by the $f^{-} \mathrm{R}$ factors $\mathrm{N}-3$ and $\mathrm{R}-15$ to both of them but not by N-1 like normal phages. It was pointed out that the suppression of these transductions by the $f^{-} \mathrm{R}$ factors was less severe than the reductions of EOP and lysogenization with these phages.

The adsorption of phage P-22 to LT-2 was not affected by any $\mathbf{R}$ factors. Similar findings have been obtained with phages $\lambda$ and T1 in K-12 (31). It was demonstrated that the injection of the nucleic acids of phages $T 1$ and $\lambda$ is not detectably affected by the presence of any $R$ factors.

It was further shown that the nucleic acids of phages $T 1$ and $\lambda$ grown on $R^{-}$cells of $K-12$ are broken down in bacteria carrying $f^{-} \mathrm{R}$ factors. These results of the injection of the phage nucleic acids and of their breakdown in restrictive bacteria indicate that the broken-down phage nucleic acids remain inside the cells if the bacteria are not treated with trichloroacetic acid. The nucleic acids of phages $\mathrm{T} 1$ and $\lambda$ modified by $\mathrm{N}-3$ were not broken down in the bacteria carrying N-3 and $\mathrm{R}-15$, but underwent breakdown in bacteria carrying N-1. Less than $10 \%$ of the unmodified phage nucleic acids were broken down in cells carrying $f^{+} \mathbf{R}$ factor 222 and in $\mathbf{R}^{-}$cells, where no restriction is observed. About an equal extent of breakdown of nucleic acids was found with modified phages. It is not known whether this small fraction of breakdown of the phage nucleic acids is an artifact. Similar findings have been obtained by Dussoix and Arber (12) and Fukasawa (14) in their systems. Thus, the mechanism of suppression of formation of phage plaques by $f^{-} \mathbf{R}$ factors seems likely to be due to the breakdown of the injected phage nucleic acids, although there is an alternative possibility that this breakdown is a mere result of restriction (19). At any rate, the agent(s) responsible for the breakdown of the phage nucleic acids must be a deoxyribonuclease(s), because the phages listed above as restricted by the $f^{-} \mathbf{R}$ factors are all known to contain deoxyribonucleic acid (DNA) as their genetic material. Phage W-31 is not an exception (T. Miyake, personal communication). The modified phages may contain DNA with "host specificity" $(3,4)$, since they are not sensitive to this enzyme. The fact that the DNA of the phages, which were modified to $\mathrm{N}-3$ and $\mathrm{R}-15$, remain sensitive to breakdown in the cells with $\mathrm{N}-1$ seems to suggest that these deoxyribonucleases are specifically formed by the presence of the $f^{-} \mathbf{R}$ factors and that the enzyme specified by N-1 is different from that specified by N-3 and R-15. There is an alternative possibility: the enzyme responsible for the breakdown of the phage DNA is a normal component of the cell and the injected phage DNA undergoes some change which protects the DNA from the action of the enzyme, whereas this change does not occur in the restrictive bacteria (19). As in phage $\lambda$, spontaneous as well as ultraviolet-induced production of phage P-22 in lysogenic LT-2 was not affected by any R factors. One may suspect that this is due to the modification of prophages by $f^{-} \mathbf{R}$ factors. But this is not the case at least in N-1, because this $R$ factor does not modify these phages. Furthermore, zygotic induction of phage $\lambda$ was not affected by any $R$ factors. Thus, the phage nucleic acids, which are present as prophages in the bacteria carrying $f^{-} \mathrm{R}$ factors, and which are transferred to the restrictive cells together with the host chromosome, are apparently able to replicate normally. Arber and Morse (5), Boyer (6), and Pittard (27) reported that the recombination frequencies and the linkage of chromosomal genes were reduced in the cross of $\mathrm{Hfr}$ strains with the restrictive $\mathrm{F}^{-}$recipients and that these reductions are due to the breakdown of the transferred chromosome. We could not find any measurable reduction by $f^{-} \mathbf{R}$ factors of the recombination of chromosomal genes in the crosses of $\mathrm{R}^{-} \mathbf{H f r}$ with $\mathrm{F}^{-} \mathrm{R}^{+}$strains (unpublished data). These results suggest that the enzyme responsible for the breakdown of the phage DNA in our systems may be located near the cell surface and that the chromosome transferred by conjugation and prophage $\lambda$ attached to it may be somehow protected from this enzyme(s). In fact, Cordonnier and Bernardi (10) showed that endonuclease I is located near the cell wall, and Molholt and Fraser (23) found that the restriction of phages is removed upon conversion of restrictive $E$. coli to spheroplasts. We have recently shown, however, that endonuclease $I$ is not involved with the mechanism of restriction of phages by $f^{-} \mathbf{R}$ factors by our finding that these phages are still restricted in an endonuclease I-less mutant of $E$. coli carrying $f^{-}$factors. These results will be reported in a separate paper. Our failure to show the restriction of bacterial chromosomes by $f^{-} \mathbf{R}$ factors might merely be due to the much weaker restriction compared to that by prophage $\mathbf{P l}$.

The fact that transductions are less severely suppressed by $f^{-} \mathbf{R}$ factors than is the formation of phage plaques may be interpreted by assuming that the bacterial chromosomal genes in the transducing phage particles have a greater chance of surviving the inactivation by the nuclease. In other words, this difference may be due to the difference in target sizes between the DNA molecules of phages and chromosomal genes. Suppression of lysogenization with temperate phages by $f^{-} \mathbf{R}$ factors is easily and reasonably accounted for by the breakdown of the injected phage DNA. 
N-3 and R-15 have so far exhibited identical patterns in the restriction and modification of various phages (Table 9), and also in their superinfection immunity (31). However, we have recently found that the restriction of the phages by R-15 but not by N-3 is temperature-sensitive. This finding is now under investigation and will be reported in a following paper.

It was further shown that the average burst size of phage T1 is reduced by the presence of $f^{-} \mathrm{R}$ factors, in one-step growth as well as in singleburst experiments. This point was not studied with other phages but, since the plaque sizes of phages $\lambda$ and P-22, both modified and unmodified, on the indicators with $\mathrm{N}-3$ and $\mathrm{R}-15$ are slightly smaller than those on the indicators with $f^{+} \mathbf{R}$ factors and without $\mathrm{R}$ factors, it is likely that the progeny formation of these phages is also suppressed slightly by the presence of $f^{-} \mathbf{R}$ factors. The reason for the small plaque size of the phages on the indicators with $\mathrm{N}-1$ was previously interpreted as being due to the absence of modification of the phages (31). These results indicate that the formation of progeny phage by the phage DNA which escaped enzymatic breakdown after injection remains sensitive to some inhibitory mechanism in the cells with $f^{-} \mathrm{R}$ factors.

\section{ACKNOWLEDGMENTS}

We are indebted to D. Ushiba, $H$. Uetake, T. Fukasawa, and S. Toyama for helpful discussions.

This investigation was supported by Public Health Service research grant AI-04740 from the National Institute of Allergy and Infectious Diseases, and by a research grant from the Ministry of Education, Japan.

\section{Literature Cited}

1. Adams, M. H. 1950. Methods of study of bacterial viruses. Methods Med. Res. 2:1-73.

2. Arber, W. 1964. Host specificity of DNA produced by Escherichia coli. III. Effects of transduction mediated by $\lambda$ dg. Virology 23:173-182.

3. ARBER, W. 1965. Host-controlled modification of bacteriophage. Ann. Rev. Microbiol. 19:365-378.

4. Arber, W., AND D. Dussoix. 1962. Host specificity of DNA produced by Escherichia coli. I. Host controlled modification of bacteriophage $\lambda$. J. Mol. Biol. 5:18-36.

5. Arber, W., AND M. L. Morse. 1965 . Host specificity of DNA produced by Escherichia coli. VI. Effects on bacterial conjugation. Genetics $51: 137-148$.

6. BoYER, H. 1964. Genetic control of restriction and modification in Escherichia coli. J. Bacteriol. 88:1652-1660

7. Brinton, C. C., JR. 1965. The structure, function, synthesis and genetic control of bacterial pili and a molecular model for DNA and RNA transport in gram negative bacteria. Trans. N.Y. Acad. Sci. Ser. II 27:1003-1054.
8. Brinton, C. C., Jr., P. Gemski, JR., AND C. Carnahan. 1964. A new type of bacterial pilus genetically controlled by the fertility factor of $E$. coli $\mathrm{K} 12$ and its role in chromosome transfer. Proc. Natl. Acad. Sci. U.S. 52:776-783.

9. Britten, R. J., AND R. B. Roberts. 1960. Highresolution density gradient sedimentation analysis. Science 131:32-33.

10. Cordonnier, C., and G. Bernardi. 1965. Localization of $E$. coli endonuclease I. Biochem. Biophys. Res. Commun. 20:555-559.

11. Demerec, M., and Z. Hartman. 1956. Tryptophan mutants in Salmonella typhimurium. Carnegie Inst. Wash. Publ. 612:5-17.

12. Dusioix, D., AND W. Arber. 1962. Host specificity of DNA produced by Escherichia coli. II. Control over acceptance of DNA from infecting phage $\lambda$. J. Mol. Biol. 5:37-49.

13. Dussoix, D., AND W. Arber. 1965. Host specificity of DNA produced by Escherichia coli. IV. Host specificity of infectious DNA from bacteriophage $\lambda$. J. Mol. Biol. 11 :238-246.

14. Funasawa, T. 1964. The course of infection with abnormal bacteriophage T4 containing nonglucosylated DNA on Escherichia coli strains. J. Mol. Biol. 9:525-536.

15. Hershey, A. D., and M. Chase. 1952. Independent functions of viral protein and nucleic acid in growth of bacteriophage. J. Gen. Physiol. 36:39-56.

16. JACOB, F., AND E. L. WOLlman. 1954. Induction spontanée du développement du bactériophage au cours de la recombinaison génétique chez Escherichia coli. Compt. Rend. 239:455-456.

17. JaCOB, F., and E. L. Wollman. 1956. Sur les processus de conjugaison et de recombinaison génétique chez $E$. coli. I. L'induction par conjugaison ou induction zygotique. Ann. Inst. Pasteur 91:486-510.

18. JaCOB, F., AND E. L. Wollman. 1961. Sexuality and the genetics of bacteria, p.93-108. Academic Press, Inc., New York.

19. LeDERBERG, S. 1965. Host-controlled restriction and modification of deoxyribonucleic acid in Escherichia coli. Virology 27:378-387.

20. Lederberg, S., AND M. Meselson. 1964. Degradation of non-replicating bacteriophage DNA in non-accepting cells. J. Mol. Biol. 8:623-628.

21. Meynell, E., and N. Datta. 1965. Functional homology of the sex-factor and resistance transfer factors. Nature 207:884-885.

22. Meynell, E., and N. DatTa. 1966. The relation of resistance transfer factors to the $F$ factor (sex-factor) of Escherichia coli K12. Genet. Res. 7:134-140.

23. Molmolt, B., and D. Fraser. 1965. Reversal of restriction for host modified T2 and T4 DNA upon conversion of non-permissive Escherichia coli to spheroplasts. Biochem. Biophys. Res. Commun. 19:571-575.

24. Morse, M. L., E. M. Lederberg, AND J. LederBERG. 1956. Transduction in Escherichia coli K-12. Genetics 41:142-156.

25. Nomura, M., B. D. Hall, and S. Spiegelman. 
1960. Characterization of RNA synthesized in Escherichia coli after bacteriophage T2 infection. J. Mol. Biol. 2:306-326.

26. OZEKI, H. 1956. Abortive transduction in purinerequiring mutants of Salmonella typhimurium. Carnegie Inst. Wash. Publ. 612:97-106.

27. Pittard, J. 1964. Effect of phage-controlled restriction on genetic linkage in bacterial crosses. J. Bacteriol. 87:1256-1257.

28. Uetake, H., S. Toyama, and S. Hagiwara. 1964. On the mechanism of host-induced modification. Multiplicity activation and thermolabile factor responsible for phage growth restriction. Virology 22:202-213.

29. Watanabe, T., and T. Fukasawa. 1961. Episome-mediated transfer of drug resistance in Enterobacteriaceae. I. Transfer of resistance factors by conjugation. J. Bacteriol. 81 :669-678.
30. Watanabe, T., T. Fukasawa, and T. Takano. 1962. Conversion of male bacteria of Escherichia coli K-12 to resistance to f phages by infection with the episome "resistance transfer factor." Virology 17:218-219.

31. Watanabe, T., H. Nishida, C. Ogata, T. Arai, AND S. SATo. 1964. Episome-mediated transfer of drug resistance in Enterobacteriaceae. VII. Two types of naturally occurring $\mathbf{R}$ factors. $\mathbf{J}$. Bacteriol. 88:716-726.

32. Watanabe, T., and M. Okada. 1964. New type of sex factor-specific bacteriophage of Escherichia coli. J. Bacteriol. 87:727-736.

33. Yoshikawa, M., K. Miyake, and T. WakaBAYASHI. 1964. Studies on the mechanism of transfer of drug resistance in bacteria. 37 . The effect of $\mathbf{R}$ factor on the process of $\mathrm{UV}$ induction and zygotic induction of prophage $\lambda$. Med. Biol. (Tokyo) 69:344-347. 